\title{
Synergistic influence of phosphorylation and metal ions on tau oligomer formation and coaggregation with a-synuclein at the single molecule level
}

Georg Nübling ${ }^{1,2}$, Benedikt Bader ${ }^{1,2}$, Johannes Levin ${ }^{1,2}$, Jenna Hildebrandt ${ }^{1}$, Hans Kretzschmar ${ }^{1}$ and Armin Giese ${ }^{1^{*}}$

\begin{abstract}
Background: Fibrillar amyloid-like deposits and co-deposits of tau and a-synuclein are found in several common neurodegenerative diseases. Recent evidence indicates that small oligomers are the most relevant toxic aggregate species. While tau fibril formation is well-characterized, factors influencing tau oligomerization and molecular interactions of tau and a-synuclein are not well understood.

Results: We used a novel approach applying confocal single-particle fluorescence to investigate the influence of tau phosphorylation and metal ions on tau oligomer formation and its coaggregation with a-synuclein at the level of individual oligomers. We show that $\mathrm{Al}^{3+}$ at physiologically relevant concentrations and tau phosphorylation by GSK-3 $\beta$ exert synergistic effects on the formation of a distinct SDS-resistant tau oligomer species even at nanomolar protein concentration. Moreover, tau phosphorylation and $\mathrm{Al}^{3+}$ as well as $\mathrm{Fe}^{3+}$ enhanced both formation of mixed oligomers and recruitment of a-synuclein in pre-formed tau oligomers.

Conclusions: Our findings provide a new perspective on interactions of tau phosphorylation, metal ions, and the formation of potentially toxic oligomer species, and elucidate molecular crosstalks between different aggregation pathways involved in neurodegeneration.
\end{abstract}

Keywords: a-Synuclein, Metal ion, Oligomer, Phosphorylation, Tau, Iron, Aluminium, GSK-3 beta, Alzheimer's disease, Parkinson's disease

\section{Background}

Several neurodegenerative diseases comprise neuronal or glial deposits consisting mainly of protein tau, such as Alzheimer's neurofibrillary tangles (NFTs) or Pick bodies, and are therefore termed "tauopathies". In Alzheimer's Disease (AD), tau exhibits pathological hyperphosphorylation $[1,2]$, allowing both histological diagnosis by use of tau antibodies against disease specific phosphorylation sites $[3,4]$ and, to a certain extent, even in vivo diagnosis by determination of the protein's phosphorylation status in cerebrospinal fluid $[5,6]$.

\footnotetext{
* Correspondence: armin.giese@med.uniuenchen.de

${ }^{1}$ Center for Neuropathology and Prion Research,

Ludwig-Maximilians-Universität, Feodor-Lynen-Str. 23, 81377, Munich,

Germany

Full list of author information is available at the end of the article
}

One of the most important tau kinases is Glycogen Synthase Kinase $3 \beta$ (GSK-3 $\beta$ ), which has been shown to create AD specific phospho sites on tau in vitro [7], in cell culture $[8,9]$ and in vivo $[10,11]$. Some $[12,13]$ but not all [14] authors reported increased GSK levels in AD brains. GSK-3 $\beta$ is colocalized with NFTs [15], and the distribution of its active form in AD brains coincides with the appearance of tau pathology [16].

Tau phosphorylation by GSK-3 $\beta$ promotes the formation of paired helical filaments (PHF) in vitro [17-19], though data concerning the relevance of this effect vary [20]. An enhancing impact of GSK-3 $\beta$ on tau aggregation was also demonstrated in cell culture and in vivo [21-23], supporting a possible role of this kinase in $A D$ pathogenesis. Furthermore, phosphorylation influences metal ion induced tau aggregation. Several studies

\section{Ciomed Central}


demonstrated that tau phosphorylation enhances $\mathrm{Al}^{3+}$ induced aggregation [24,25] or even is a prerequisite for such aggregation [26,27].

The influence of aluminium on tau aggregation has been extensively studied, since the metal ion was shown to induce NFT-like deposits in mammalian brain after intracerebral injection [28]. Though aluminium levels were found to be raised in AD hippocampus [29] and the metal ion was colocalized with NFTs and early tau deposits in brain sections [30,31], its relevance to AD pathogenesis is still unclear, especially due to the inconsistent outcome of epidemiological studies [32].

In vitro studies examining effects of ferric iron $\left(\mathrm{Fe}^{3+}\right)$ yielded results resembling those obtained for aluminium. $\mathrm{Fe}^{3+}$ also induces the aggregation of phosphorylated protein tau [27], is colocalized with NFTs [30,33,34] and elevated in AD hippocampus and amygdala [35]. Furthermore, $\mathrm{Fe}^{3+}$ induces $\alpha$-synuclein ( $\alpha$-syn) aggregation [36-38].

Co-deposits of tau and $\alpha$-syn have been found in several neurodegenerative diseases, and interactions between these two proteins recently gained increasing interest. $\alpha$-Syn has been detected in NFTs of AD, progressive supranuclear palsy (PSP) and corticobasal degeneration (CBD) [39], whereas tau was located in Lewy bodies of patients with Dementia with Lewy bodies (DLB) [40]. In vitro, tau in solution requires inducers like heparin for filament formation, whereas the protein readily polymerizes in presence of $\alpha$-syn without inducers [41].

Furthermore, the minimal $\alpha$-syn concentration necessary for fibril formation is reduced in presence of tau, and some of the fibrils formed in presence of both proteins comprise tau and $\alpha$-syn segments [41]. Considering that both proteins are located in the cytoplasmic compartment of neurons, and that minimal concentrations of $\alpha$-syn oligomers can cross-seed tau aggregation [42], interactions of tau and $\alpha$-syn may be relevant for pathological protein aggregation in neurodegenerative diseases.

While established methods of monitoring tau and $\alpha$ syn aggregation like Thioflavin $\mathrm{T}$ assay or atomic force microscopy yield important insights in fibril formation and the formation of large oligomers, they are not suitable to directly monitor single protein interactions or interactions of different proteins. It was demonstrated that small oligomer species are on-pathway to tau filament formation [43]. Furthermore, it is increasingly recognised that prefibrillar small oligomers rather than the large NFTs might be responsible for neuronal and synaptic loss [44-46]. To investigate the influence of phosphorylation on tau oliomer formation and interactions between tau and $\alpha$-syn, we employed fluorescence correlation spectroscopy (FCS) and scanning for intensely fluorescent targets (SIFT) to investigate the influence of phosphorylation and trivalent metal ions on tau aggregation and its coaggregation with $\alpha$-syn. These methods allow monitoring of oligomerization processes at the single molecule level even at nanomolar protein concentrations $[47,48]$. Moreover, the possibility to label proteins with different dyes allows the investigation of tau and $\alpha$-syn interactions at the level of individual oligomers.

\section{Results}

\section{Tau phosphorylation verified by western blot and SIFT}

Mass spectroscopy showed that recombinant protein tau is of high purity and does not contain significant amounts of cleavage products (Figure 1A). Notably, fluorescence labeling of tau with Alexa dyes did not alter the protein's electrophoretic mobility, though mass spectroscopy showed an increase in tau's molecular weight after labeling (data not shown). We confirmed in vitro phosphorylation of human recombinant tau by demonstrating a typical band shift of the protein in western blot (see Figure 1B) [17]. We further evaluated whether the SIFT method can be employed to detect phosphorylated protein tau by labeling with Alexa-488 tagged antibodies AT-8 and T46. While T46 detects both phosphorylated and unphosphorylated tau, the AT-8 antibody requires the protein to be phosphorylated at specific sites (Goedert et al, 1995). The A $\beta$ specific antibody $6 \mathrm{E} 10$ was used as a negative control. SIFT analysis shows that both $\mathrm{T} 46^{488}$ and AT- ${ }^{488}$, but not $6 \mathrm{E} 10^{488}$ bind to phosphorylated tau ${ }^{647}$ (pTau, Figure 1C), while only $\mathrm{T} 46^{488}$ binds to mock phosphorylated tau ${ }^{647}$ (mTau, also see materials and methods section).

\section{Influence of phosphorylation on tau aggregation induced by aluminium and DMSO}

Our previous studies revealed that the organic solvent DMSO and the metal ion aluminium $\left(\mathrm{Al}^{3+}\right)$ induce the formation of distinct tau oligomer species [49]. In order to evaluate the influence of protein phosphorylation on the effects of these aggregation inducers, we employed GSK-3 $\beta$ to create phosphorylated tau (pTau) and compared its aggregation behavior to mock phosphorylated tau (mTau). Our findings show that oligomerization of both pTau and mTau can be induced by $1 \%$ DMSO, with mTau showing a higher rate of aggregation than pTau $(\mathrm{p}<0.001$, Figure 2A). Conversely, in presence of $10 \mu \mathrm{M}$ $\mathrm{Al}^{3+}$, pTau oligomerization exceeds mTau $(\mathrm{p}<0.05)$, with the overall aggregation level being distinctly higher compared to DMSO for both pTau and mTau (also see Additional files 1 and 2).

2D histograms of detected aggregates show the formation of distinct oligomer species in presence of DMSO and $\mathrm{Al}^{3+}$ (Figure $2 \mathrm{~B}$ ). In presence of $\mathrm{DMSO}$, tau protein 


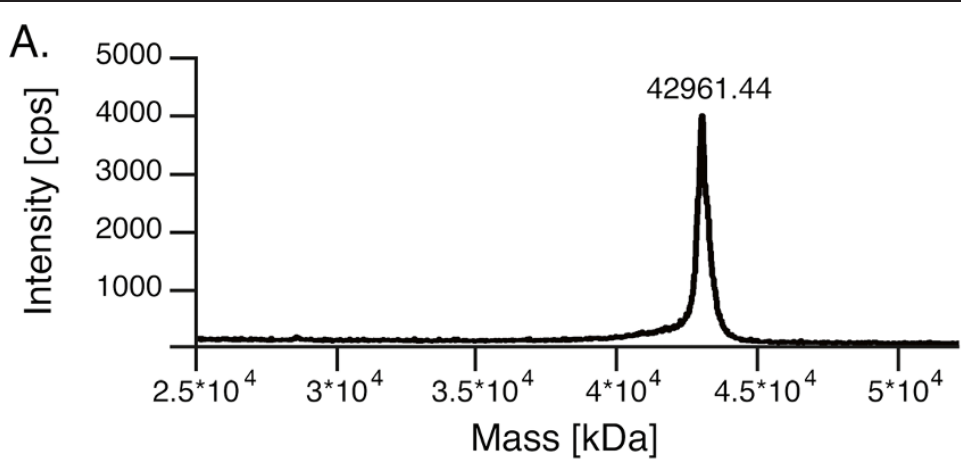

B.
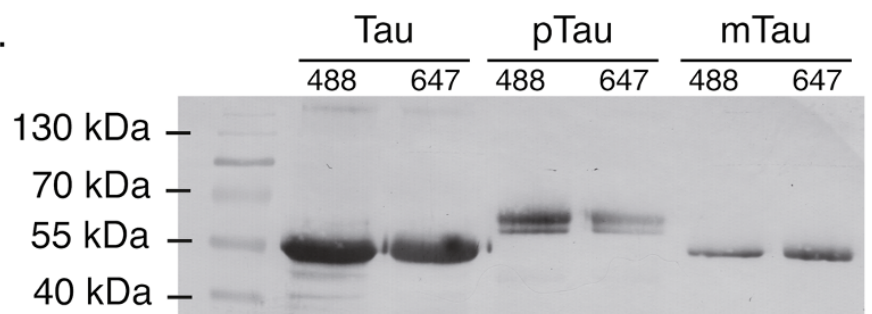

$25 \mathrm{kDa}-$

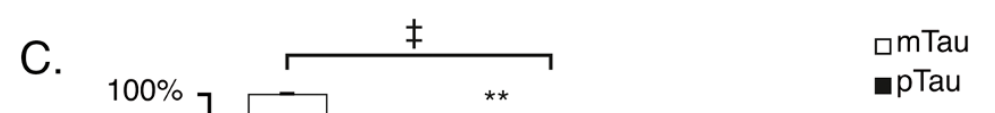

Figure 1 (See legend on next page.) 
(See figure on previous page.)

Figure 1 Tau phosphorylation verified by western blot and SIFT analysis. A. Mass spectroscopy showed that recombinant human tau (isoform 5, $42967 \mathrm{Da}$ ) is of high purity. B. While mock phosphorylation (mTau) does not influence SDS-PAGE mobility of recombinant tau, a typical band shift is observed upon tau phosphorylation (pTau). C. SIFT analysis showed labeling of pTau oligomers with the phosphorylated tau specific AT-8 antibody in presence of 1\% DMSO indicating antibody binding, while no coaggregation was observed with mTau. Data was normalized against the coaggregation level of mTau with the T46 antibody, which does not require tau phosphorylation. 2D histograms depicting antibody ( $\mathrm{x}$-axis) and protein (y-axis) interactions show coaggregates of T46 with both pTau and mTau, while AT-8 only coaggregates with pTau. A scheme describing the appearance of mixed aggregates in 2D histograms is included in Figure 3 . Upon combining AT-8 and mTau, only DMSO induced tau aggregates are visible along the $y$-axis, similar to the control antibody 6E10. Measurements were taken from 12 independent samples; each sample was measured four times. Levels of significance are displayed as * $=p<0.05$; ${ }^{* *}=p<0.01 ;+=p<0.001$.

shows only moderate aggregation, while $\mathrm{Al}^{3+}$ enhances the formation of larger oligomers with higher fluorescence intensity.

Fluorescence intensity distribution analysis (FIDA) of tau oligomers induced by DMSO yielded larger aggregates for mTau (mean 76 molecules) than for pTau (mean 26 molecules). In presence of $\mathrm{Al}^{3+}$, large tau oligomers comprising on average 240 (pTau) and 220 (mTau) molecules occurred within 15 minutes, while the overall aggregation level was higher for pTau (Figure 2A, for aggregation dynamics also see Additional file 3 ). The combination of DMSO and $\mathrm{Al}^{3+}$ increased aggregation levels compared to $\mathrm{Al}^{3+}$ alone predominantly for mTau (also see Additional files 1 and 2).

Furthermore, we examined the SDS stability of oligomers generated by the different enhancers (Figure $2 \mathrm{C}$, D). While DMSO induced aggregates dissolve upon addition of the ionic detergent SDS in a final concentration of $0.2 \%$, more than $50 \%$ of the $\mathrm{Al}^{3+}$ induced oligomer signal remains stable $100 \mathrm{~min}$ after addition of SDS.

In conclusion, $\mathrm{Al}^{3+}$ promotes rapid formation of detergent resistant oligomers, preferably of phosphorylated protein tau. Conversely, DMSO induced aggregation is diminished upon tau phosphorylation.

Influence of tau phosphorylation on the coaggregation of monomeric tau and a-synuclein in presence of metal ions and organic solvents

Since the role of tau and $\alpha$-syn coaggregation is increasingly recognized, we investigated the effect of tau ${ }^{488}$ phosphorylation on its coaggregation with $\alpha-\operatorname{syn}^{647}$. As previous work has shown a major influence of $\mathrm{Fe}^{3+}$ on $\alpha$-syn oligomerization [36-38], we also used $\mathrm{Fe}^{3+}$ at a final concentration of $10 \mu \mathrm{M}$ in our assay.

In these experiments, $1 \%$ DMSO promoted the coaggregation of tau and $\alpha$-syn in a similar manner for pTau and mTau (Figure 3A). On average, coaggregates were composed of 11 pTau $+8 \alpha$-syn monomers or 15 mTau + $12 \alpha$-syn monomers, respectively, as determined by FIDA analysis. $\mathrm{Fe}^{3+}$ also had a promotional influence on coaggregation, which was higher for pTau $(\mathrm{p}<0.01$, on average 53 pTau $+10 \alpha$-syn and 39 mTau $+3 \alpha$-syn monomers per oligomer). Upon combining DMSO and
$\mathrm{Fe}^{3+}$, an additional effect exceeding the influence of one inducer alone can be seen (also see Additional files 4 and 5), while no significant difference in aggregation levels of pTau and mTau was detectable. Similar to our tau oligomerization experiments, $\mathrm{Al}^{3+}$ was the strongest inducer of tau and $\alpha$-syn coaggregation, with pTau showing higher coaggregation activity than mTau $(\mathrm{p}<$ 0.001 , Figure $3 \mathrm{~A}$; on average 131 pTau $+115 \alpha$-syn and $137 \mathrm{mTau}+80 \alpha$-syn monomers per oligomer). This difference was still detectable when combining $\mathrm{Al}^{3+}$ with DMSO, though to a lesser extent $(\mathrm{p}<0.05)$. Mixed oligomers comprising both tau and $\alpha$-syn appear scattered around the bisectrix of these histograms, while homogeneous aggregates are located close to the axes, as illustrated in Figure 3D.

Concerning oligomer stability, $0.2 \%$ SDS reduced the number of coaggregates formed in presence of every tested agent (Figure 3B, C). Again, coaggregates formed in presence of metal ions proved to be more resistant to SDS than those induced by DMSO, though to an overall lesser extent than the homogeneous tau aggregates. Oligomer sizes before and after addition of SDS as determined by FIDA analysis are provided in Additional file 6. The presence of $\mathrm{Al}^{3+}$-induced, SDS stable mixed oligomers was further validated applying gel filtration and fluorescence spectroscopy. In these experiments, $\mathrm{Al}^{3+}$ induced oligomers were separated from monomers by gel filtration. SDS stable mixed tau and $\alpha$-syn oligomers eluted prior to monomers, as demonstrated by crosscorrelation and SIFT-2D analysis (see Additional file 7).

Thus, our data show increased tau and $\alpha$-syn coaggregation after tau phosphorylation in presence of trivalent metal ions, and that the heterogenic oligomers generated by $\mathrm{Fe}^{3+}$ and $\mathrm{Al}^{3+}$ are more stable to SDS treatment than those formed by DMSO.

\section{Coaggregation of tau oligomers and monomeric a-synuclein}

Giasson et al. showed that tau and $\alpha$-syn induce each other's filament formation, and that some of the fibrils formed in presence of both proteins comprise tau and $\alpha$-syn segments [41]. Such findings suggest that these segments are either assembled by end to end annealing 
Tau aggregation:
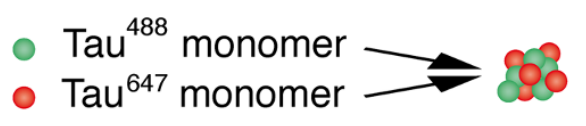

A.

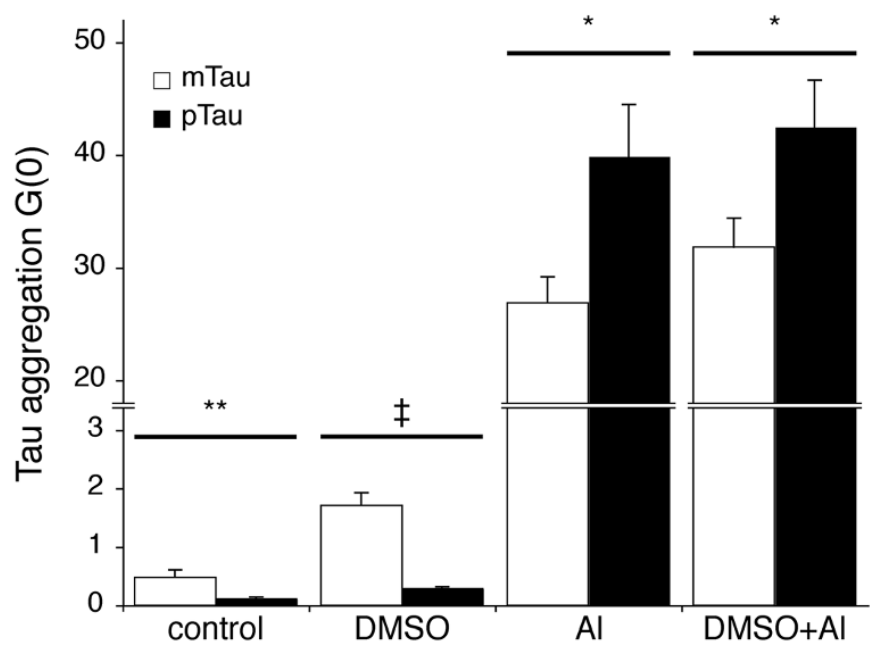

B.

mTau

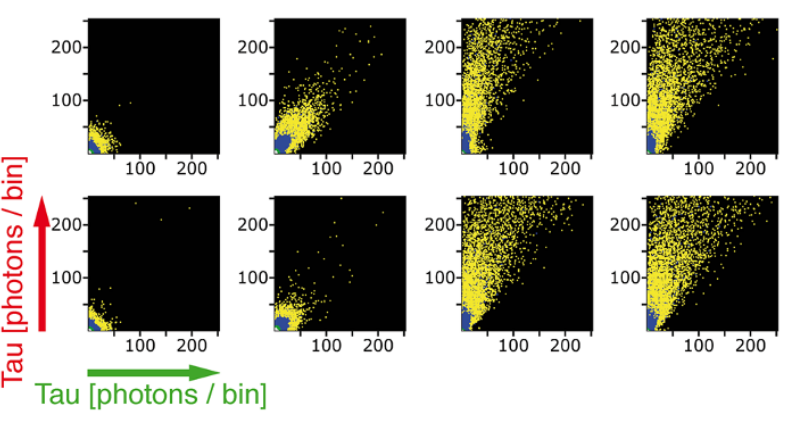

C.

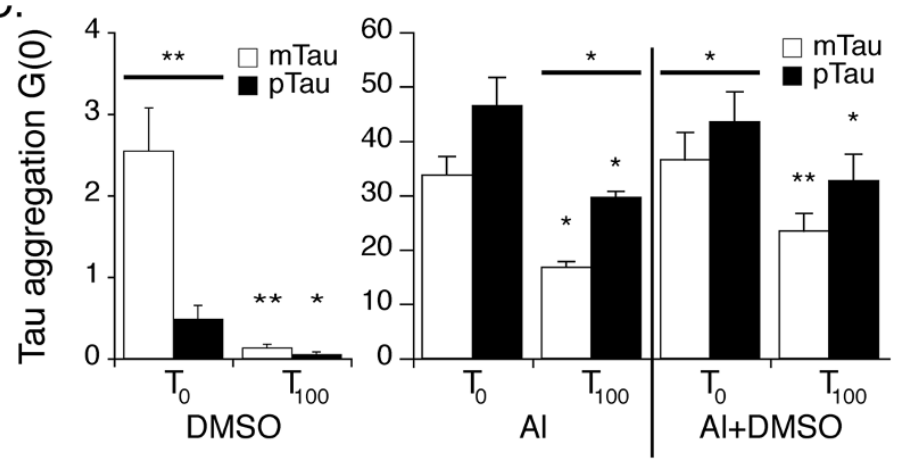

D.

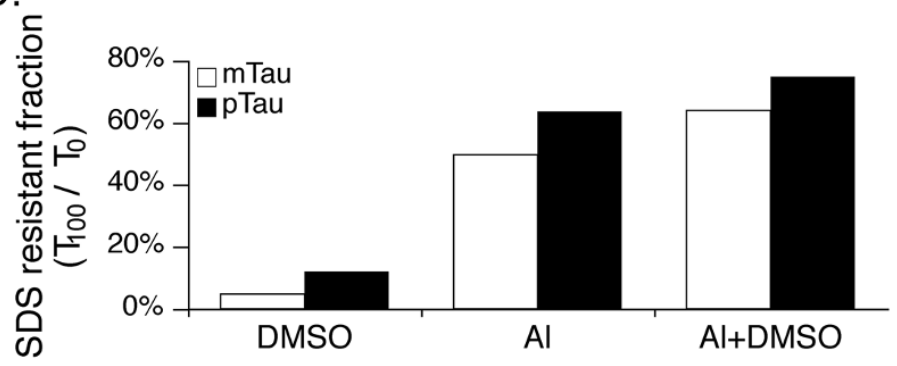

Figure $\mathbf{2}$ (See legend on next page.) 
(See figure on previous page.)

Figure $\mathbf{2} \mathrm{Al}^{3+}$ promotes the formation of SDS stable tau oligomers more efficiently after tau phosphorylation. A. Cross-correlation amplitudes $\left(G(0)\right.$ ) show mild proaggregatory activity of the organic solvent DMSO, which was significantly higher for mTau. $\mathrm{Al}^{3+}$ promotes intense protein oligomerization. Measurements were taken from 15 independent samples; each sample was measured four times. B. 2D histograms of detected photons indicate the formation of smaller oligomers in presence of DMSO (mean 76 monomers per oligomer for mTau, 26 monomers for pTau) compared to $\mathrm{Al}^{3+}$ (mean 220 to 240 monomers per oligomer). C. Cross correlation amplitude immediately before ( $\left.T_{0}\right)$ and 100 min after $\left(T_{100}\right)$ addition of SDS to the aggregation assay. Significant reductions of aggregation levels at $T_{100}$ are indicated by the symbols over the error bars, while significant differences between pTau and mTau are indicated by the symbols over the wide bars. Measurements were taken from 7 independent samples. D. Cross correlation amplitude at $T_{100}$ normalized against $T_{0}$ shows increased SDSresistance of $\mathrm{Al}^{3+}$ induced oligomers compared to DMSO. Levels of significance are displayed as ${ }^{*}=p<0.05 ;{ }^{* *}=p<0.01 ; *=p<0.001$.

of short filament fragments, or that such fragments act as seeds for both proteins. To evaluate the effect of tau phosphorylation on the interaction of tau oligomers with monomeric $\alpha$-syn, tau ${ }^{488}$ was first incubated in presence of $1 \%$ DMSO, $10 \mu \mathrm{M} \mathrm{Fe}{ }^{3+}, 10 \mu \mathrm{M} \mathrm{Al}^{3+}$, and combinations of these agents for 90 minutes to generate preformed tau oligomers. $\alpha-S_{y n}{ }^{647}$ monomers were then added to the assay and measurements were conducted (Figure 4A).

Contrary to the experiments with tau monomers, DMSO had a stronger effect on the coaggregation of pre-formed mTau oligomers with monomeric $\alpha$-syn compared to pTau oligomers $(p<0.05$, Figure $4 \mathrm{~A})$. Under these conditions, coaggregates contained on average 20 pTau $+2 \alpha$-syn monomers or 27 mTau $+5 \alpha$-syn monomers, respectively.

pTau oligomer coaggregation with monomeric $\alpha$-syn exceeded mTau seven- to ninefold in presence of $\mathrm{Fe}^{3+}$ $(\mathrm{p}<0.01$; on average $197 \mathrm{pTau}+14 \alpha$-syn or $175 \mathrm{mTau}+$ $3 \alpha$-syn monomers per oligomer) and $\mathrm{Al}^{3+}(\mathrm{p}<0.001$; on average 151 pTau $+73 \alpha$-syn or 154 mTau $+35 \alpha$-syn monomers per oligomer). This difference was markedly reduced upon combining $\mathrm{Fe}^{3+}$ and 1\% DMSO, which again yielded a synergistic effect compared to the two inducers alone (also see Additional files 8 and 9). The combination of $\mathrm{Al}^{3+}$ and 1\% DMSO also reduced the difference between pTau and mTau to a two-fold excess of pTau coaggregation $(\mathrm{p}<0.01)$.

SDS $(0.2 \%)$ reduced the number of oligomers formed in presence of every tested inducer (Figure 4B). Especially aggregates induced by metal ions alone showed enhanced resistance to SDS treatment compared to those formed in presence of DMSO (Figure 4C).

\section{Discussion}

Several studies have dealt with the influence of protein phosphorylation and the metal ion aluminium $\left(\mathrm{Al}^{3+}\right)$ on tau filament formation so far [17-27]. However, the pathophysiological relevance of these factors is still unclear. Whereas most studies were mainly focused on tau filament formation, we applied single molecule fluorescence techniques to investigate the influence of these factors on early tau aggregation steps and oligomer formation. We demonstrate that tau phosphorylation modulates oligomer formation in presence of $\mathrm{Al}^{3+}$, and that $\mathrm{Al}^{3+}$ induces the formation of distinct large, SDS resistant tau oligomers.

We further demonstrate that coaggregation of tau and $\alpha$-syn can be observed at the single molecule level, is differentially modulated by tau phosphorylation, and induced by trivalent metal ions. Such coaggregation might be of pathophysiological relevance, since co-deposits of tau and $\alpha$-syn have been detected in various neurodegenerative diseases $[39,40]$.

\section{Influence of tau phosphorylation on electrophoretic mobility and antibody interaction}

It has been demonstrated that in vitro phosphorylation of human protein tau by GSK-3 $\beta$ can be verified using SDS-PAGE by demonstrating a complete band shift of phosphorylated tau compared to the unphosphorylated protein [17]. We verified efficient tau phosphorylation indicated by a complete band shift compared to the unphosporylated protein (Figure 1B). In addition, we investigated whether fluorescently labeled antibodies can be employed in the SIFT method to verify tau phosphorylation at nanomolar protein concentrations, allowing for possible diagnostic implementations of this method in the future. Our data corroborate that tau phosphorylation was successful and that antibodies can be employed in the SIFT method to identify proteins and posttranslational modifications such as phosphorylation at nanomolar protein concentrations (Figure 1C). Such an assay may provide a valuable tool for future diagnostic applications e.g. the detection of novel specific CSF biomarkers of neurodegeneration.

\section{Differential influence of phosphorylation on tau aggregation}

In vitro studies have yielded conflicting results regarding the influence of tau phosphorylation on its assembly to filaments. To date, both inhibitory and promotional effects of GSK-3 $\beta$ mediated phosphorylation on tau filament assembly were found in absence or presence of polyanionic aggregation inducers [17-20,50,51]. Notably, for $\mathrm{Al}^{3+}$ induced tau aggregation, phosphorylation was 


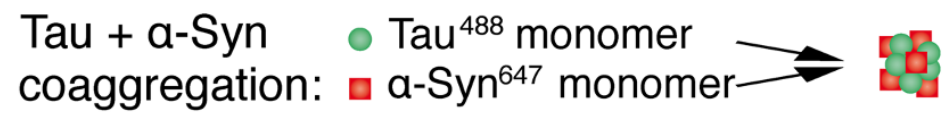

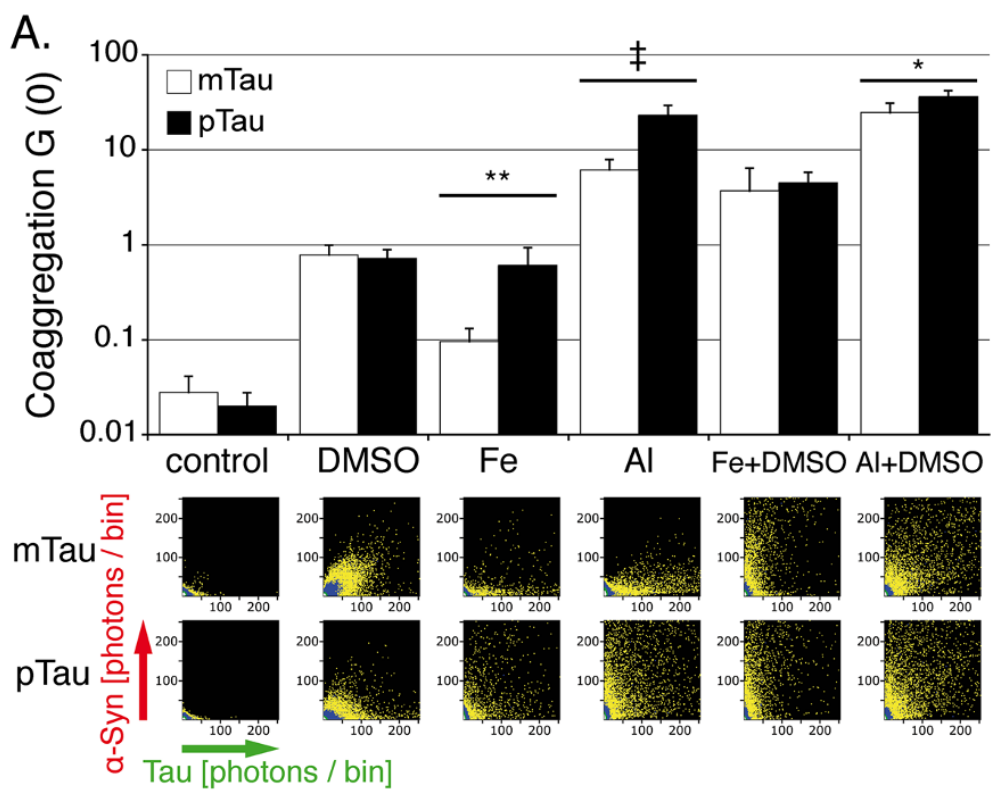

B.

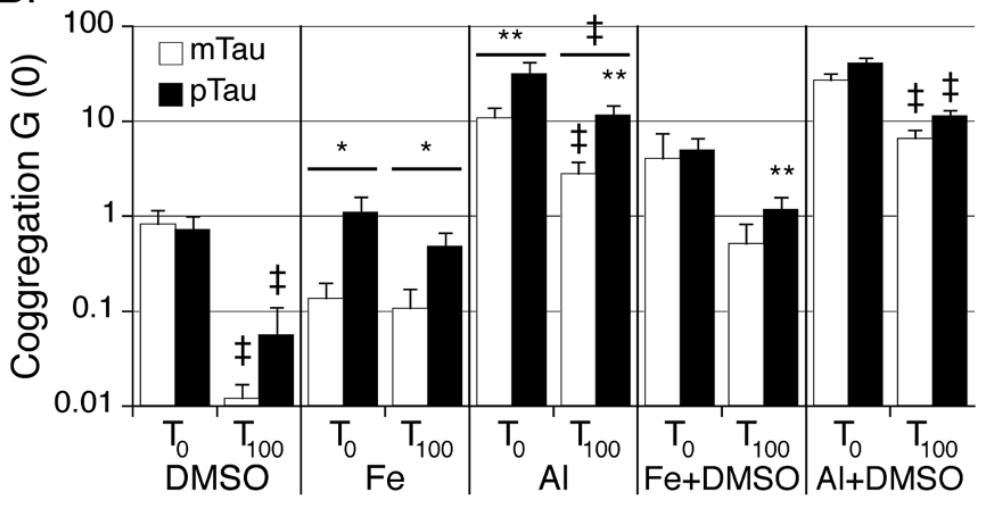

C.

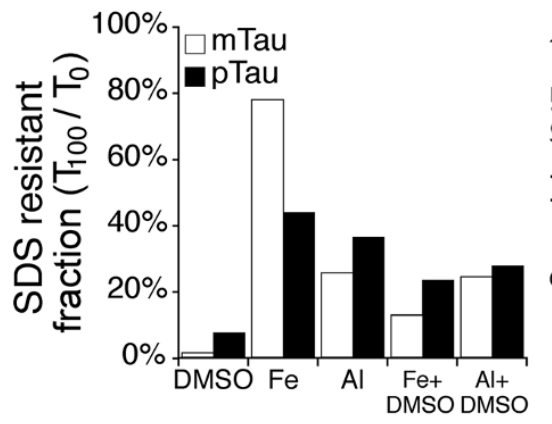

D.

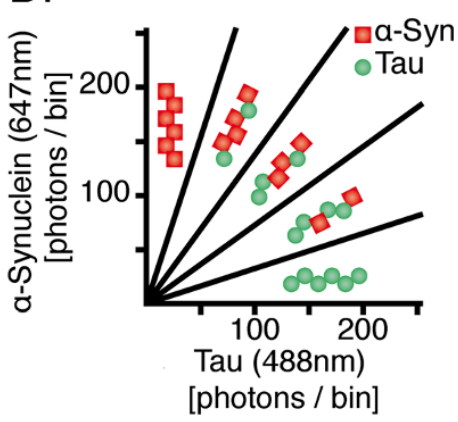

Figure 3 (See legend on next page.)

consistently found to be enhancing or, in some experiments, even a prerequisite [24-27].

However, the methods applied in these studies, such as electron microscopy, thioflavine fluorescence, laser light scattering, SDS-PAGE and western blot, are of limited use in directly examining single molecule interactions at the oligomer level. Furthermore, these techniques often require high concentrations of both protein and aggregation 
(See figure on previous page.)

Figure $3 \mathrm{Al}^{3+}$ promotes stronger formation of SDS stable tau and a-syn coaggregates than $\mathrm{Fe}^{3+}$, preferably after tau phosphorylation. A. Cross-correlation amplitudes $(\mathrm{G}(0))$ show mild proaggregatory activity of DMSO and $\mathrm{Fe}^{3+}$, while $\mathrm{Al}^{3+}$ promotes intense protein oligomerization. Combinations of DMSO and metal ions show a synergistic effect especially for mTau. 2D histograms show the formation of smaller oligomers induced by DMSO compared to $\mathrm{Al}^{3+}$. B. Cross-correlation amplitude before $\left(T_{0}\right)$ and $100 \mathrm{~min}$ after $\left(\mathrm{T}_{100}\right)$ addition of SDS to the aggregation assay. Significant reductions of aggregation levels at $T_{100}$ are indicated by the symbols over the error bars, while significant differences between pTau and mTau are indicated by the symbols over the wide bars. C. Cross correlation amplitude at $\mathrm{T}_{100}$ normalized against $T_{0}$ shows increased SDS-resistance of metal ion induced oligomers compared to DMSO. D. Scheme illustrating the appearance of tau and a-syn aggregates and coaggregates of the two proteins. Higher fluorescence intensities of detected oligomers indicate increased oligomer size. Measurements were taken from 16 independent samples; each sample was measured four times. Levels of significance are displayed as ${ }^{*}=p<0.05 ;{ }^{* *}=p<0.01 ;+p<0.001$.

inducer that might not depict physiological conditions, especially given the fact that tau protein readily polymerizes at high concentrations without any inducer [52,53]. In addition, the majority of studies investigating brain $\mathrm{Al}^{3+}$ concentrations did not detect concentrations exceeding 10 $\mu \mathrm{g} / \mathrm{g}$ brain mass (dry weight) in AD brains [54], which approximately corresponds to $60 \mu \mathrm{mol} / \mathrm{kg}$ (wet weight), while many studies examining the influence of $\mathrm{Al}^{3+}$ on tau aggregation in vitro applied $\mathrm{Al}^{3+}$ concentrations in the milimolar range $[25,27,55]$.

In this study, we applied confocal single molecule fluorescent techniques to investigate the influence of protein phosphorylation by GSK-3 $\beta$ on tau oligomer formation at the single molecule level at nanomolar concentrations. Exposure to $10 \mu \mathrm{M} \mathrm{Al}^{3+}$ induced the rapid formation of large tau oligomers, while DMSO at a final concentration of $1 \%$ led to the formation of smaller oligomers. The large $\mathrm{Al}^{3+}$ triggered oligomers contained an average of 220 to 240 molecules as shown by FIDA analysis, and were resistant to treatment with $0.2 \%$ SDS, which in contrast readily dissolved the smaller oligomers formed in presence of DMSO. The oligomer sizes observed here were comparable with data presented earlier [49]. Interestingly, phosphorylation by GSK-3 $\beta$ yielded an increase in $\mathrm{Al}^{3+}$ induced tau oligomer formation, while oligomer size was comparable for pTau and mTau.

Thus, our data identify tau phosphorylation and physiological concentrations of the metal ion $\mathrm{Al}^{3+}$ as synergistic inducers of the formation of SDS resistant tau oligomers even at nanomolar protein concentrations. These findings substantiate the hypothesis that $\mathrm{Al}^{3+}$ may play a role in the formation of neurotoxic oligomers even at early stages of neurodegeneration.

\section{Metal ions and organic solvents enhance tau and a-synunclein coaggregation depending on tau's phosphorylation status}

Co-deposits of tau and $\alpha$-syn have been found in several neurodegenerative diseases, including AD, PSP, CBD and DLB $[39,40]$. Since interactions of different proteins are difficult to monitor in vitro, only few studies investigating the interaction of tau and $\alpha$-syn have been published so far. It was demonstrated that in mixed micromolar solutions of $\alpha$-syn and tau, both proteins' minimal concentrations for filament assembly are decreased [41,56]. Moreover, Giasson et al. detected filaments that comprised both tau and $\alpha$-syn, proving that the two proteins directly interact in mixed solutions [41]. A more recent study showed that $\alpha$-syn fibrils can be taken up by tau overexpressing cells and induce the formation of phosphorylated triton-insoluble tau oligomers [57]. In vivo studies further demonstrated that tau deposits can be found in mice overexpressing pathologic human $\alpha$-syn mutations [58].

In this study, we demonstrate that coaggregation of tau and $\alpha$-syn takes place even at nanomolar protein concentrations, is strongly induced by trivalent metal ions, and differentially modulated by tau's phosphorylation status. In contrast to the findings of Giasson et al., we did not detect tau and $\alpha$-syn coaggregation in the absence of aggregation inducers. This apparent discrepancy is most likely explained by the differences in protein concentrations (up to 1000-fold) and the shorter observation time [41]. However, our data demonstrate that tau and $\alpha$-syn coaggregation occurs even at nanomolar protein concentrations in presence of aggregation inducers. As in our tau aggregation assay, $\mathrm{Al}^{3+}$ had the most pronounced effect on coaggregation of $\alpha$-syn with tau monomers and oligomers. $\mathrm{Al}^{3+}$ induces rapid coaggregation of tau and $\alpha$-syn (see Additional file 3 ). $\mathrm{Fe}^{3+}$ and DMSO also induce coaggregation of the two proteins, though to an overall lesser extent. In our experiments, tau phosphorylation by GSK-3 $\beta$ strongly enhanced the formation of mixed oligomers induced by $\mathrm{Al}^{3+}$ or $\mathrm{Fe}^{3+}$. Moreover, the mixed oligomers resulting from metal ion induced coaggregation proved to be more resistant to SDS treatment than those formed in presence of DMSO.

We further provide data from FIDA analysis and gel filtration experiments demonstrating the presence and size of mixed tau and a-syn oligomers (see Additional files 6 and 7). Earlier studies applying atomic force micoscropy and SIFT established FIDA-based quantification of oligomer sizes as a reliable method [38].

These results extend the current model of tau and $\alpha$-syn interaction at early stages of neurodegeneration. 


\section{Tau + a-Syn 89 Tau $^{488}$ oligomer
coaggregation: $a$ a-Syn 647 monomer $\longrightarrow$ Fag}

A.
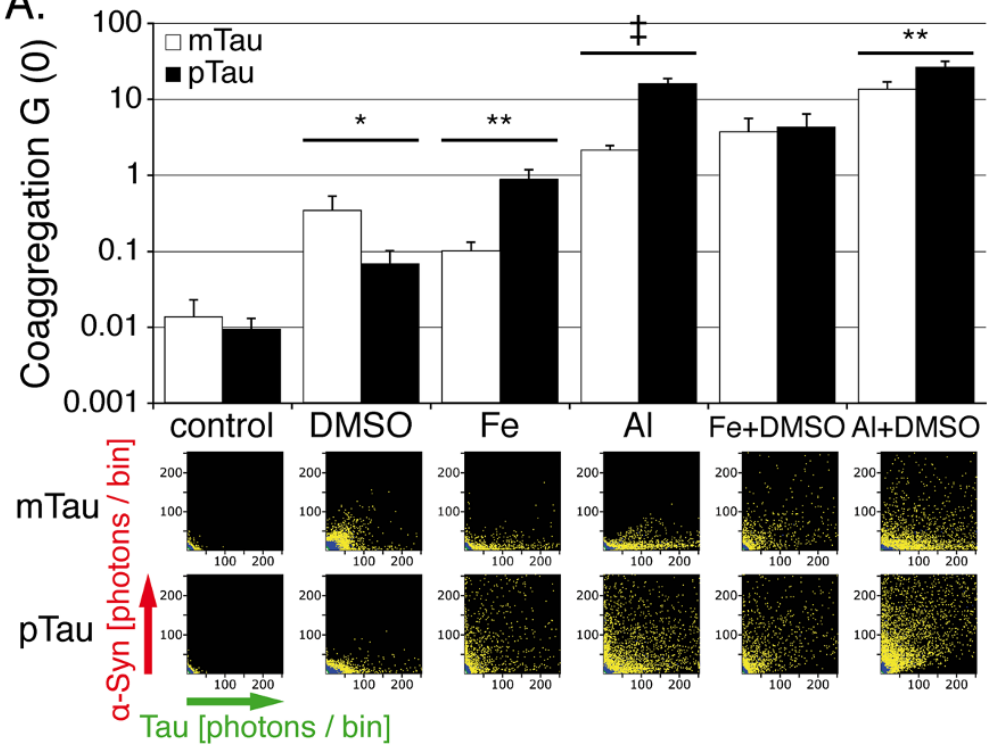

B.

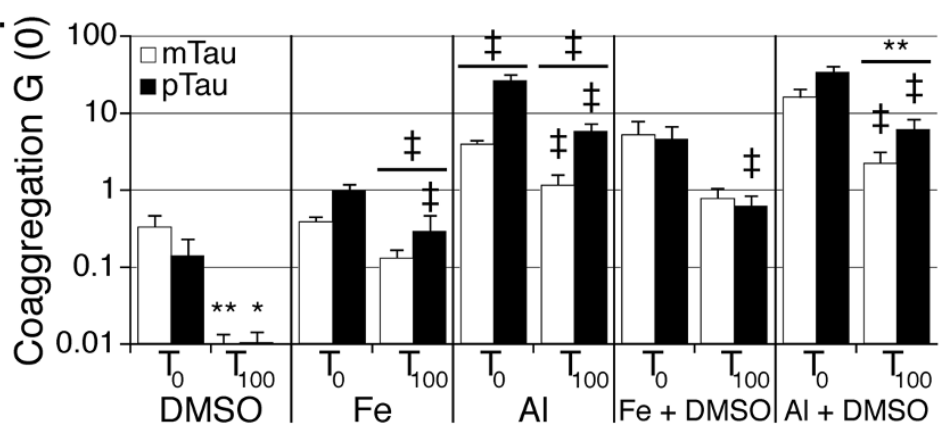

C.

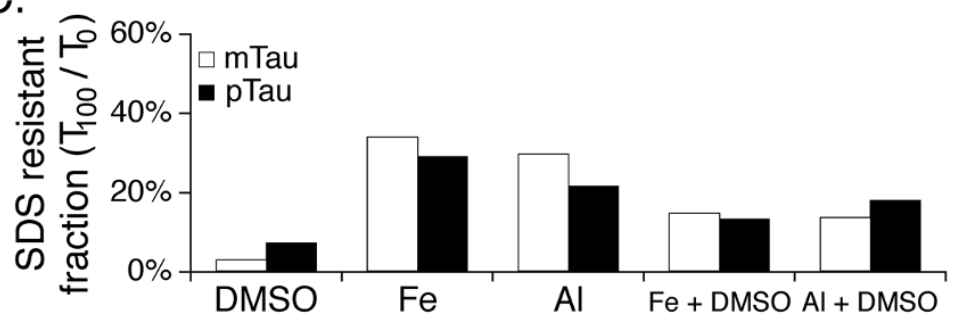

Figure 4 Monomeric a-syn preferably coaggregates with pTau oligomers in presence of metal ions. A. Cross-correlation amplitudes (G (0)) show mild coaggregation of a-syn monomers with pre-formed tau oligomers induced by DMSO and $\mathrm{Fe}^{3+}$, while $\mathrm{Al}^{3+}$ promotes intense coaggregation. Combinations of DMSO and metal ions show a synergistic effect especially for mTau. 2D histograms show the formation of smaller mixed oligomers induced by DMSO compared to the metal ions. B. Cross-correlation amplitude before $\left(T_{0}\right)$ and 100 min after $\left(T_{100}\right)$ addition of SDS to the aggregation assay. Significant reductions of aggregation levels at $\mathrm{T}_{100}$ are indicated by the symbols over the error bars, while significant differences between pTau and mTau are indicated by the symbols over the wide bars. C. Cross correlation amplitude at $T_{100}$ normalized against $T_{0}$ shows increased SDS-resistance of metal ion induced oligomers compared to DMSO. Measurements were taken from 20 independent samples; each sample was measured four times. Levels of significance are displayed as ${ }^{*}=p<0.05 ;{ }^{*}=p<0.01 ;+=p<0.001$. 
As the cytoplasmic concentration of unbound tau and $\alpha$-syn is low in pre-clinical neurodegeneration, the presence of pro-aggregatory factors may be crucial in the generation of early mixed oligomers. We identify trivalent metal ions and tau phosphorylation by GSK-3 $\beta$ as potential inducers of such oligomer formation even at nanomolar protein concentrations. A time-dependent increase of oligomer concentrations may then induce self-propagating and cross-seeding mechanisms as demonstrated by Giasson and Waxman [41,57].

\section{Conclusions}

In summary, we demonstrate that tau phosphorylation and trivalent metal ions such as $\mathrm{Al}^{3+}$ act together in the formation of distinct SDS resistant tau oligomers. Moreover, applying confocal single molecule fluorescence techniques, we show that, under certain conditions, interactions of tau and $\alpha$-syn can take place even at nanomolar protein concentrations, and result in the formation of mixed oligomers. Notably, the formation of SDS resistant mixed aggregates was induced by physiologically relevant concentrations of trivalent metal ions, and strongly enhanced by tau phosphorylation. Taking into account that a considerable amount of soluble tau exists in a phosphorylated state in neurodegenerative diseases $[1,2,59]$, these findings support a crucial role of specific metal ions such as $\mathrm{Al}^{3+}$ and $\mathrm{Fe}^{3+}$ in early cytoplasmic aggregation and coaggregation events.

Moreover, our results indicate common pathophysiologic mechanisms of both tau aggregation and crossseeding phenomena, and might explain the coincidence of tau and $\alpha$-syn in neuronal deposits. The mixed aggregates described here may provide an interlink of different pathological pathways leading to neurodegeneration, and may serve as promising therapeutic targets for future drug development. Furthermore, we introduce a novel technique of monitoring post-translational modifications at very low protein concentrations that may provide a powerful diagnostic tool in the future.

\section{Methods}

\section{Expression of human proteins tau and a-synuclein Protein tau}

Tau isoform 5 was expressed in E.coli as described previously [49]. In brief, thermocompetent E.coli DE3 (RIL) were transformed, and tau was purified by sterile filtration, cation exchange chromatography and ammonium acid salt precipitation. The transformation vector was a kind gift of Manuela Neumann (ZNP Munich/Zurich).

\section{a-Synuclein}

$\alpha$-Synuclein was produced according to established protocols [48]. A stock solution containing $1 \mathrm{mg} / \mathrm{ml} \alpha$-synuclein was prepared in $50 \mathrm{mM}$ tris buffer, $\mathrm{pH}$ 7.0.

\section{Protein labeling}

Proteins were labeled with fluorescent dyes Alexa-488-Osuccinimidylester and Alexa-647-O-succinimidylester, respectively, as described previously [48]. Tau isoform 5 was incubated with a four-fold molar excess of Alexa-488 or Alexa-647 in $100 \mathrm{mM} \mathrm{NaHCO} 3$ for $24 \mathrm{~h}$ at room temperature. For $\alpha$-syn, a two-fold molar excess of dye was used. Antibodies T46 (Invitrogen, Carlsbad, CA), AT8 (Pierce Endogen, Rockford, IL) and 6E10 (Acris Antibodies, Hiddenhausen, Germany) first underwent buffer exchange to PBS pH 7.0. Since antibody concentrations after buffer exchange were unknown, concentrations of Alexa-488-O-succinimidylester were determined empirically. Unbound dye was separated using a PD10 desalting column. Fluorescently labeled proteins are further referred to as $\operatorname{tau}^{488}$, tau ${ }^{647}$, and $\alpha-\operatorname{syn}^{647}$.

\section{Phosphorylation of protein tau}

Tau phosphorylation was conducted as described previously [17]. Fluorescently labeled protein tau was incubated with Glycogen Synthase Kinase $3 \beta$ (Sigma, Saint Louis, MO) in a ratio of 0,018 U GSK-3 $\beta$ / pmol tau in buffer containing $33 \mathrm{mM}$ tris $\mathrm{pH} 7.5,40 \mathrm{mM}$ hepes $\mathrm{pH}$ 7.64, $100 \mathrm{mM} \mathrm{NaCl}, 5 \mathrm{mM}$ EGTA, $3 \mathrm{mM} \mathrm{MgCl}$, $2 \mathrm{mM}$ ATP, $180 \mathrm{mM}$ sucrose, $0.13 \mathrm{mM}$ PMSF, $0.67 \mathrm{mM}$ benzamidine, $0.067 \%$ mercaptoethanol and $0.02 \%$ Brij-35. Samples were incubated for $20 \mathrm{~h}$ at $30{ }^{\circ} \mathrm{C}$ under constant shaking. As control, fluorescently labeled protein tau was incubated in buffer containing all components except for the enzyme, and is further referred to as mock phosphorylated tau (mTau). Protein phosphorylation was confirmed by sodium dodecyl sulfate polyacrylamide gel electrophoresis (SDS-PAGE) and western blot using antibody T46 as described previously [60]. Phosphorylated protein tau (pTau) featured a typical band shift compared to mTau, as described previously [17] (Figure 1B).

\section{Aggregation assay}

Stock solutions of tau ${ }^{488}$, tau ${ }^{647}$, and $\alpha-\operatorname{syn}^{647}$ were prepared for a final concentration of 10 molecules per focal volume, equivalent to a concentration of $10 \mathrm{nM}$ to 20 nM. For coaggregation experiments, a 1:1 ratio of tau ${ }^{488}$ and $\alpha-\operatorname{syn}^{647}$ was used. Prior to each experiment, tau samples were centrifuged at $100.000 \mathrm{~g}$ for $30 \mathrm{~min}$ to remove pre-formed aggregates, and all protein stock solutions were then controlled for pre-existing aggregates by SIFT [49]. Only samples free of pre-formed aggregates were used. All experiments were conducted in 96 well plates with a cover slide bottom, in a total sample volume of $20 \mu \mathrm{l}$ per well. Plates were covered with adhesive film to obviate evaporation. For aggregation and coaggregation experiments, protein stock solutions were added to wells containing $50 \mathrm{mM}$ tris buffer $\mathrm{pH}$ 7.0, 10 
$\mu \mathrm{M} \mathrm{AlCl}, 10 \mu \mathrm{M} \mathrm{FeCl}_{3}$ or $1 \%$ dimethyl sulfoxide (DMSO), and measurements were started immediately. For coaggregation of $\operatorname{tau}^{488}$ oligomers with $\alpha$-syn ${ }^{647}$ monomers, samples of tau ${ }^{488}$ were prepared as described above and pre-incubated for $90 \mathrm{~min}$. Subsequently, $\alpha-$ syn $^{647}$ monomers were added and measurements were started immediately. To investigate oligomer stability, a 10-fold SDS stock solution for a final concentration of $0.2 \%$ was added to each well after each experiment, and measurements were repeated. Each well was measured four times, resulting in a total duration of each experiment of 60 to 120 minutes, depending on experimental layout.

\section{Confocal single particle analysis}

FCS and SIFT were performed on an InsightReader (Evotec-Technologies, Hamburg, Germany) with dual color excitation at 488 and $633 \mathrm{~nm}$ as described previously $[48,49,61]$. Data was collected separately for each excitation wavelength by two single-photon detectors. Analysis was performed using FCSPP evaluation software version 2.0 (Evotec-Technologies), allowing autocorrelation, cross-correlation and fluorescence intensity distribution (FIDA) analysis, and SIFT-2D evaluation software (Evotec-Technologies). For SIFT-2D analysis, photons were added up in time intervals (bins) of $40 \mu \mathrm{s}$ and illustrated in a 2D scatterplot. Scatterplots depicted in this paper contain all photons of all consecutive measurements of one sample. Photon-weighted SIFT aggregation and coaggregation analysis was performed as described previously [49]. As cross-correlation detects small oligomeric protein aggregates with higher sensitivity, only cross-correlation data is depicted for experiments on tau aggregation and coaggregation with $\alpha$-syn (for SIFT data see Additional files 1, 4, and 7).

\section{Mass spectroscopy}

Mass spectroscopy was performed according to established protocols to verify the purity of tau protein stock solution [61].

\section{Statistical analysis}

Normal distribution of data was determined by ShapiroWilk test. If normal distribution was confirmed, a twosided student's $t$-test preceded by Levene's test for equality of variance was performed. A paired student's $t$-test was used for experiments on SDS-resistance of oligomers. If normal distribution was not confirmed, Mann-Whitney $U$-test was performed. Bonferroni-adjustment for multiple testing was done where appropriate. Data is demonstrated as average of all independent samples, and a paired student's $t$-test was performed including all independent samples. Error bars in figures show the standard error of the mean.

\section{Additional files}

Additional file 1: Comparison of aggregation levels of pTau and mTau. Comparison of aggregation levels of phosphorylated (pTau) and mock phosphorylated (mTau) protein tau in presence of different aggregation inducers. SIFT data is presented as ratios (colum / row). Measurements were taken from 15 independent samples, each sample was measured four times.

Additional file 2: Comparison of aggregation levels of pTau and mTau. Comparison of aggregation levels of phosphorylated (pTau) and mock phosphorylated (mTau) protein tau in presence of different aggregation inducers. Cross-correlation data is presented as ratios (colum / row). Measurements were taken from 15 independent samples, each sample was measured four times.

Additional file 3: Kinetics of pTau and mTau aggregation and coaggregation. Kinetics of pTau and mTau aggregation (tau/tau, 15 independent samples) and coaggregation of tau monomers (tau/a-syn, 16 independent samples) and oligomers (tau oligo/a-syn, 20

independent samples) with monomeric a-synuclein in presence of $1 \%$ DMSO, $10 \mu \mathrm{M} \mathrm{Al}^{3+}, 10 \mu \mathrm{M} \mathrm{Fe}{ }^{3+}$ and combinations of metal ions and DMSO. A control measurement depicting the aggregation status in the absence of inducers was defined as time point "0". While DMSO induces slow continuous tau aggregation, the protein's coaggregation with a-syn reaches an early steady state. $\mathrm{Al}^{3+}$ promotes rapid initial aggregation and coaggregation only for pTau, while mTau coaggregation proceeds distinctly slower. $\mathrm{Fe}^{3+}$ induced coaggregation is continuous, with pTau proceeding faster than mTau. Upon combining metal ions and DMSO, both pTau and mTau show rapid aggregation and coaggregation exceeding the single inducers. Levels of significance are displayed as ${ }^{*}=p<0.05 ;{ }^{* *}=p<0.01$; $+\mathrm{p}<0.001$.

Additional file 4: Comparison of coaggregation levels of pTau and mTau with a-syn. Comparison of coaggregation levels of phosphorylated (pTau) and mock phosphorylated (mTau) protein tau with a-synuclein in presence of different aggregation inducers. SIFT data is presented as ratios (colum / row). Measurements were taken from 16 independent samples, each sample was measured four times.

Additional file 5: Comparison of coaggregation levels of pTau and $\mathbf{m T a u}$ with a-syn. Comparison of coaggregation levels of phosphorylated (pTau) and mock phosphorylated (mTau) protein tau with a-synuclein in presence of different aggregation inducers. Crosscorrelation data is presented as ratios (colum / row). Measurements were taken from 16 independent samples, each sample was measured four times.

Additional file 6: Quantification of mixed tau and a-syn oligomer sizes. Fluorescence intensity distribution analysis (FIDA) shows the size of metal ion induced mixed tau and a-syn oligomers before and after addition of SDS. SDS stable mixed oligomers can further be demonstrated in SIFT-2D analysis.

Additional file 7: Separation of SDS stable mixed tau and a-syn oligomers by gel filtration. Mixed tau and a-syn oligomers induced by $\mathrm{Al}^{3+}$ are separated from monomers applying gel filtration. SDS-stable oligomers are eluted before tau and a-syn monomers, as demonstrated by crosscorrelation and SIFT analysis.

Additional file 8: Comparison of coaggregation levels of pTau and mTau oligomers with a-syn. Comparison of coaggregation levels of phosphorylated (pTau) and mock phosphorylated (mTau) tau oligomers with monomeric a-synuclein in presence of different aggregation inducers. SIFT data is presented as ratios (colum / row). Measurements were taken from 20 independent samples, each sample was measured four times.

Additional file 9: Comparison of coaggregation levels of pTau and $\mathrm{mTau}$ oligomers with a-syn. Comparison of coaggregation levels of phosphorylated (pTau) and mock phosphorylated (mTau) tau oligomers with monomeric a-synuclein in presence of different aggregation inducers. Cross-correlation data is presented as ratios (colum / row). Measurements were taken from 20 independent samples, each sample was measured four times. 


\section{Abbreviations}

AD: Alzheimer's disease; a-syn: a-synuclein; CBD: Corticobasal degeneration; DLB: Dementia with Lewy bodies; DMSO: dimethyl sulfoxide;

FCS: Fluorescence correlation spectroscopy; FIDA: fluorescence intensity

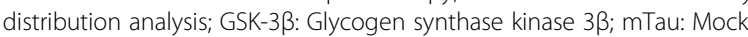
phosphorylated tau; NFT: Neurofibrillary tangles; PAGE: Polyacrylamide ge electrophoresis; PHF: Paired helical filaments; pTau: Phosphorylated tau; PSP: Progressive supranuclear palsy; SDS: Sodium dodecyl sulfate; SIFT: Scanning for intensely fluorescent targets.

\section{Competing interests}

The authors declare that they have no competing interests.

Authors' contributions
$G N^{1} \cdot A, B, C ; 2 . A, B, C ; 3 . A, B, B B^{1} . A, B: 2 . A, C ; 3 . B, J L^{1} . A, B ; 2 . C ; 3 . B, J H^{2} . A, B, C ; 3 . A, B$ $H^{1}$. B; 3. B $, A G^{1} \cdot A, B ; 2 . A, C_{;}^{\prime} 3 . B$. Author contributions are abbreviated as follows: $1=$ Research project: A. Conception, B. Organization, C. Execution. $2=$ Statistical Analysis: A. Design, B. Execution, C. Review and Critique. $3=$ Manuscript Preparation: A. Writing of the first draft, B. Review and Critique. All authors read and approved the final manuscript.

\section{Acknowledgements}

We thank Manuela Neumann for providing the tau expression vector. We further thank Lars Israel for conducting the mass spectroscopy analysis of recombinant tau. This work was supported by SFB 596. Parts of this work are elements of one author's dissertation (Georg Nuebling) presented to the Medical Faculty, LMU Munich, Germany.

\section{Author details}

${ }^{1}$ Center for Neuropathology and Prion Research,

Ludwig-Maximilians-Universität, Feodor-Lynen-Str. 23, 81377, Munich, Germany. ${ }^{2}$ Neurologische Klinik und Poliklinik, Klinikum der Universität München, Marchioninistr. 15, 81377, Munich, Germany.

Received: 12 March 2012 Accepted: 30 June 2012

Published: 23 July 2012

\section{References}

1. Khatoon S, Grundke-labal I, labal K: Brain levels of microtubule-associated protein tau are elevated in Alzheimer's disease: a radioimmuno-slot-blot assay for nanograms of the protein. J Neurochem 1992, 59:750-753.

2. Kopke E, Tung YC, Shaikh S, Alonso AC, Iqbal K, Grundke-lqbal I: Microtubule-associated protein tau. Abnormal phosphorylation of a nonpaired helical filament pool in Alzheimer disease. J Biol Chem 1993, 268:24374-24384.

3. Goedert M, Jakes R, Vanmechelen E: Monoclonal antibody AT8 recognises tau protein phosphorylated at both serine 202 and threonine 205. Neurosci Lett 1995, 189:167-169.

4. Buee-Scherrer V, Condamines O, Mourton-Gilles C, Jakes R, Goedert M, Pau B, Delacourte $A: A D 2$, a phosphorylation-dependent monoclonal antibody directed against tau proteins found in Alzheimer's disease. Brain Res Mol Brain Res 1996, 39:79-88.

5. Buerger K, Ewers M, Pirttila T, Zinkowski R, Alafuzoff I, Teipel SJ, DeBernardis J, Kerkman D, McCulloch C, Soininen H, Hampel H: CSF phosphorylated tau protein correlates with neocortical neurofibrillary pathology in Alzheimer's disease. Brain 2006, 129:3035-3041.

6. Hampel H, Buerger K, Zinkowski R, Teipel SJ, Goernitz A, Andreasen N, Sjoegren M, DeBernardis J, Kerkman D, Ishiguro K, et al: Measurement of phosphorylated tau epitopes in the differential diagnosis of Alzheimer disease: a comparative cerebrospinal fluid study. Arch Gen Psychiatry 2004, 61:95-102

7. Reynolds CH, Betts JC, Blackstock WP, Nebreda AR, Anderton BH: Phosphorylation sites on tau identified by nanoelectrospray mass spectrometry: differences in vitro between the mitogen-activated protein kinases ERK2, c-Jun N-terminal kinase and P38, and glycogen synthase kinase-3beta. J Neurochem 2000, 74:1587-1595.

8. Lovestone S, Reynolds CH, Latimer D, Davis DR, Anderton BH, Gallo JM, Hanger D, Mulot S, Marquardt B, Stabel S, et al: Alzheimer's disease-like phosphorylation of the microtubule-associated protein tau by glycogen synthase kinase-3 in transfected mammalian cells. Curr Biol 1994, 4:1077-1086.
9. Li X, Lu F, Tian Q, Yang Y, Wang Q, Wang JZ: Activation of glycogen synthase kinase-3 induces Alzheimer-like tau hyperphosphorylation in rat hippocampus slices in culture. J Neural Transm 2006, 113:93-102.

10. Spittaels K, Van den Haute C, Van Dorpe J, Geerts H, Mercken M, Bruynseels K, Lasrado R, Vandezande K, Laenen I, Boon T, et al: Glycogen synthase kinase3beta phosphorylates protein tau and rescues the axonopathy in the central nervous system of human four-repeat tau transgenic mice. J Biol Chem 2000, 275:41340-41349.

11. Brownlees J, Irving NG, Brion JP, Gibb BJ, Wagner U, Woodgett J, Miller CC: Tau phosphorylation in transgenic mice expressing glycogen synthase kinase-3beta transgenes. Neuroreport 1997, 8:3251-3255.

12. Pei JJ, Tanaka T, Tung YC, Braak E, lqbal K, Grundke-lqbal I: Distribution, levels, and activity of glycogen synthase kinase-3 in the Alzheimer disease brain. J Neuropathol Exp Neurol 1997, 56:70-78.

13. Leroy K, Yilmaz Z, Brion JP: Increased level of active GSK-3beta in Alzheimer's disease and accumulation in argyrophilic grains and in neurones at different stages of neurofibrillary degeneration. Neuropathol Appl Neurobiol 2007, 33:43-55.

14. Baum L, Hansen L, Masliah E, Saitoh T: Glycogen synthase kinase 3 alteration in Alzheimer disease is related to neurofibrillary tangle formation. Mol Chem Neuropathol 1996, 29:253-261.

15. Yamaguchi H, Ishiguro K, Uchida T, Takashima A, Lemere CA, Imahori K: Preferential labeling of Alzheimer neurofibrillary tangles with antisera for tau protein kinase (TPK) l/glycogen synthase kinase-3 beta and cyclindependent kinase 5, a component of TPK II. Acta Neuropathol 1996, 92:232-241.

16. Pei JJ, Braak E, Braak H, Grundke-lqbal I, lqbal K, Winblad B, Cowburn RF: Distribution of active glycogen synthase kinase 3beta (GSK-3beta) in brains staged for Alzheimer disease neurofibrillary changes. $J$ Neuropathol Exp Neurol 1999, 58:1010-1019.

17. Rankin CA, Sun Q, Gamblin TC: Tau phosphorylation by GSK-3beta promotes tangle-like filament morphology. Mol Neurodegener 2007, 2:12.

18. Liu F, Li B, Tung EJ, Grundke-lqbal I, lqbal K, Gong CX: Site-specific effects of tau phosphorylation on its microtubule assembly activity and selfaggregation. Eur J Neurosci 2007, 26:3429-3436.

19. Wang JZ, Grundke-lqbal I, lqbal K: Kinases and phosphatases and tau sites involved in Alzheimer neurofibrillary degeneration. Eur J Neurosci 2007, 25:59-68.

20. Voss K, Gamblin TC: GSK-3beta phosphorylation of functionally distinct tau isoforms has differential, but mild effects. Mol Neurodegener 2009, 4:18.

21. Vandebroek T, Vanhelmont T, Terwel D, Borghgraef P, Lemaire K, Snauwaert J, Wera S, Van Leuven F, Winderickx J: Identification and isolation of a hyperphosphorylated, conformationally changed intermediate of human protein tau expressed in yeast. Biochemistry 2005, 44:11466-11475.

22. Jackson GR, Wiedau-Pazos M, Sang TK, Wagle N, Brown CA, Massachi S, Geschwind DH: Human wild-type tau interacts with wingless pathway components and produces neurofibrillary pathology in Drosophila. Neuron 2002, 34:509-519.

23. Engel T, Goni-Oliver P, Lucas JJ, Avila J, Hernandez F: Chronic lithium administration to FTDP-17 tau and GSK-3beta overexpressing mice prevents tau hyperphosphorylation and neurofibrillary tangle formation, but preformed neurofibrillary tangles do not revert. J Neurochem 2006, 99:1445-1455.

24. Li W, Ma KK, Sun W, Paudel HK: Phosphorylation sensitizes microtubuleassociated protein tau to $\mathrm{Al}(3+)$-induced aggregation. Neurochem Res 1998, 23:1467-1476.

25. Haase C, Stieler JT, Arendt T, Holzer M: Pseudophosphorylation of tau protein alters its ability for self-aggregation. J Neurochem 2004, 88:1509-1520.

26. Shin RW, Lee VM, Trojanowski JQ: Aluminum modifies the properties of Alzheimer's disease PHF tau proteins in vivo and in vitro. J Neurosci 1994, 14:7221-7233.

27. Yamamoto A, Shin RW, Hasegawa K, Naiki H, Sato H, Yoshimasu F, Kitamoto T: Iron (III) induces aggregation of hyperphosphorylated tau and its reduction to iron (II) reverses the aggregation: implications in the formation of neurofibrillary tangles of Alzheimer's disease. J Neurochem 2002, 82:1137-1147.

28. Klatzo I, Wisniewski H, Streicher E: Experimental Production of Neurofibrillary Degeneration. I. Light Microscopic Observations. $J$ Neuropathol Exp Neurol 1965, 24:187-199.

29. Xu N, Majidi V, Markesbery WR, Ehmann WD: Brain aluminum in Alzheimer's disease using an improved GFAAS method. Neurotoxicology 1992, 13:735-743. 
30. Good PF, Perl DP, Bierer LM, Schmeidler J: Selective accumulation of aluminum and iron in the neurofibrillary tangles of Alzheimer's disease: a laser microprobe (LAMMA) study. Ann Neurol 1992, 31:286-292.

31. Walton JR: Aluminum in hippocampal neurons from humans with Alzheimer's disease. Neurotoxicology 2006, 27:385-394.

32. Krewski D, Yokel RA, Nieboer E, Borchelt D, Cohen J, Harry J, Kacew S, Lindsay J, Mahfouz AM, Rondeau V: Human health risk assessment for aluminium, aluminium oxide, and aluminium hydroxide. $J$ Toxicol Environ Health B Crit Rev 2007, 10(Suppl 1):1-269.

33. Smith MA, Harris PL, Sayre LM, Perry G: Iron accumulation in Alzheimer disease is a source of redox-generated free radicals. Proc Natl Acad Sci $U$ S A 1997, 94:9866-9868.

34. Morris CM, Kerwin JM, Edwardson JA: Non-haem iron histochemistry of the normal and Alzheimer's disease hippocampus. Neurodegeneration 1994, 3:267-275

35. Deibel MA, Ehmann WD, Markesbery WR: Copper, iron, and zinc imbalances in severely degenerated brain regions in Alzheimer's disease: possible relation to oxidative stress. J Neurol SCi 1996, 143:137-142.

36. Levin J, Högen T, Hillmer A, Bader B, Schmidt F, Kretzschmar H, Bötzel K, Giese A: Generation of ferric iron links oxidative stress to a-synuclein oligomer formation. J Parkinson's Dis 2011, 1:205-216.

37. Hillmer AS, Putcha P, Levin J, Hogen T, Hyman BT, Kretzschmar H, McLean PJ, Giese A: Converse modulation of toxic alpha-synuclein oligomers in living cells by N'-benzylidene-benzohydrazide derivates and ferric iron. Biochem Biophys Res Commun 2010, 391:461-466.

38. Kostka M, Hogen T, Danzer KM, Levin J, Habeck M, Wirth A, Wagner R, Glabe CG, Finger $S$, Heinzelmann $U$, et al: Single particle characterization of ironinduced pore-forming alpha-synuclein oligomers. J Biol Chem 2008, 283:10992-11003.

39. Takeda A, Hashimoto M, Mallory M, Sundsumo M, Hansen L, Masliah E: C terminal alpha-synuclein immunoreactivity in structures other than Lewy bodies in neurodegenerative disorders. Acta Neuropatho/ 2000, 99:296-304.

40. Ishizawa T, Mattila P, Davies P, Wang D, Dickson DW: Colocalization of tau and alpha-synuclein epitopes in Lewy bodies. J Neuropathol Exp Neurol 2003, 62:389-397.

41. Giasson Bl, Forman MS, Higuchi M, Golbe LI, Graves CL, Kotzbauer PT, Trojanowski JQ, Lee VM: Initiation and synergistic fibrillization of tau and alpha-synuclein. Science 2003, 300:636-640.

42. Lasagna-Reeves CA, Castillo-Carranza DL, Guerrero-Muoz MJ, Jackson GR, Kayed R: Preparation and characterization of neurotoxic tau oligomers. Biochemistry 2010, 49:10039-10041.

43. Maeda S, Sahara N, Saito Y, Murayama M, Yoshiike Y, Kim H, Miyasaka T, Murayama S, Ikai A, Takashima A: Granular tau oligomers as intermediates of tau filaments. Biochemistry 2007, 46:3856-3861.

44. Santacruz K, Lewis J, Spires T, Paulson J, Kotilinek L, Ingelsson M, Guimaraes A DeTure M, Ramsden M, McGowan E, et al: Tau suppression in a neurodegenerative mouse model improves memory function. Science 2005, 309:476-481.

45. Wittmann CW, Wszolek MF, Shulman JM, Salvaterra PM, Lewis J, Hutton M, Feany MB: Tauopathy in Drosophila: neurodegeneration without neurofibrillary tangles. Science 2001, 293:711-714.

46. Kimura T, Fukuda T, Sahara N, Yamashita S, Murayama M, Mizoroki T, Yoshiike Y, Lee B, Sotiropoulos I, Maeda S, Takashima A: Aggregation of detergent-insoluble tau is involved in neuronal loss but not in synaptic loss. J Biol Chem 2010, 285:38692-38699.

47. Bieschke J, Giese A, Schulz-Schaeffer W, Zerr I, Poser S, Eigen M, Kretzschmar H: Ultrasensitive detection of pathological prion protein aggregates by dualcolor scanning for intensely fluorescent targets. Proc Natl Acad Sci U S A 2000, 97:5468-5473.

48. Giese A, Bader B, Bieschke J, Schaffar G, Odoy S, Kahle PJ, Haass C, Kretzschmar $\mathrm{H}$ : Single particle detection and characterization of synuclein co-aggregation. Biochem Biophys Res Commun 2005, 333:1202-1210.

49. Bader B, Nubling G, Mehle A, Nobile S, Kretzschmar H, Giese A: Single particle analysis of tau oligomer formation induced by metal ions and organic solvents. Biochem Biophys Res Commun 2011, 411:190-196.

50. Schneider A, Biernat J, von Bergen M, Mandelkow E, Mandelkow EM: Phosphorylation that detaches tau protein from microtubules (Ser262, Ser214) also protects it against aggregation into Alzheimer paired helical filaments. Biochemistry 1999, 38:3549-3558.
51. Sun Q, Gamblin TC: Pseudohyperphosphorylation causing AD-like changes in tau has significant effects on its polymerization. Biochemistry 2009, 48:6002-6011.

52. Crowther RA, Olesen OF, Smith MJ, Jakes R, Goedert M: Assembly of Alzheimer-like filaments from full-length tau protein. FEBS Lett 1994 337:135-138.

53. Perez M, Valpuesta JM, Medina M, Montejo de Garcini E, Avila J: Polymerization of tau into filaments in the presence of heparin: the minimal sequence required for tau-tau interaction. J Neurochem 1996, 67:1183-1190.

54. Andrasi E, Pali N, Molnar Z, Kosel S: Brain aluminum, magnesium and phosphorus contents of control and Alzheimer-diseased patients. J Alzheimers Dis 2005, 7:273-284.

55. Yang LS, Ksiezak-Reding $\mathrm{H}: \mathrm{Ca} 2+$ and $\mathrm{Mg} 2+$ selectively induce aggregates of PHF-tau but not normal human tau. J Neurosci Res 1999, 55:36-43.

56. Kotzbauer PT, Giasson BI, Kravitz AV, Golbe LI, Mark MH, Trojanowski JQ, Lee VM: Fibrillization of alpha-synuclein and tau in familial Parkinson's disease caused by the A53T alpha-synuclein mutation. Exp Neurol 2004, 187:279-288.

57. Waxman EA, Giasson BI: Induction of Intracellular Tau Aggregation Is Promoted by a-Synuclein Seeds and Provides Novel Insights into the Hyperphosphorylation of Tau. J Neurosci 2011, 31:7604-7618.

58. Emmer KL, Waxman EA, Covy JP, Giasson BI: E46K human alpha-synuclein transgenic mice develop Lewy-like and tau pathology associated with age-dependent, detrimental motor impairment. J Biol Chem 2011, 286:35104-35118.

59. Ksiezak-Reding H, Liu WK, Yen SH: Phosphate analysis and dephosphorylation of modified tau associated with paired helical filaments. Brain Res 1992, 597:209-219.

60. Arai T, Guo JP, McGeer PL: Proteolysis of non-phosphorylated and phosphorylated tau by thrombin. J Biol Chem 2005, 280:5145-5153.

61. Levin J, Giese A, Boetzel K, Israel L, Hogen T, Nubling G, Kretzschmar H, Lorenzl S: Increased alpha-synuclein aggregation following limited cleavage by certain matrix metalloproteinases. Exp Neurol 2009, 215:201-208.

doi:10.1186/1750-1326-7-35

Cite this article as: Nübling et al:: Synergistic influence of phosphorylation and metal ions on tau oligomer formation and coaggregation with a-synuclein at the single molecule level. Molecular Neurodegeneration 2012 7:35.

\section{Submit your next manuscript to BioMed Central and take full advantage of:}

- Convenient online submission

- Thorough peer review

- No space constraints or color figure charges

- Immediate publication on acceptance

- Inclusion in PubMed, CAS, Scopus and Google Scholar

- Research which is freely available for redistribution

Submit your manuscript at www.biomedcentral.com/submit
C Biomed Central 